\title{
Reconstruction of putative DNA virus from endogenous rice tungro bacilliform virus-like sequences in the rice genome: implications for integration and evolution
}

\author{
Motoyuki Kunii $^{\dagger 1}$, Masanori Kanda ${ }^{\dagger 1}$, Hironori Nagano ${ }^{1}$, Ichiro Uyeda ${ }^{2}$, \\ Yuji Kishima*1 and Yoshio Sano ${ }^{1}$
}

Address: ${ }^{1}$ Laboratory of Plant Breeding, Graduate School of Agriculture, Hokkaido University, Sapporo 060-8589, Japan and ${ }^{2}$ Laboratory of Plant Pathology, Graduate School of Agriculture, Hokkaido University, Sapporo 060-8589, Japan

Email: Motoyuki Kunii - Qnii@mb3.seikyou.ne.jp; Masanori Kanda - kanda-ma@abs.agr.hokudai.ac.jp;

Hironori Nagano - nagano@abs.agr.hokudai.ac.jp; Ichiro Uyeda - uyeda@res.agr.hokudai.ac.jp; Yuji Kishima* - kishima@abs.agr.hokudai.ac.jp; Yoshio Sano - rysano@abs.agr.hokudai.ac.jp

* Corresponding author †Equal contributors

Published: 18 October 2004

BMC Genomics 2004, 5:80 doi:10.1 186/147|-2164-5-80

This article is available from: http://www.biomedcentral.com/I47I-2164/5/80

(C) 2004 Kunii et al; licensee BioMed Central Ltd.

This is an open-access article distributed under the terms of the Creative Commons Attribution License (http://creativecommons.org/licenses/by/2.0), which permits unrestricted use, distribution, and reproduction in any medium, provided the original work is properly cited.
Accepted: 18 October 2004
Received: II June 2004

\begin{abstract}
Background: Plant genomes contain various kinds of repetitive sequences such as transposable elements, microsatellites, tandem repeats and virus-like sequences. Most of them, with the exception of virus-like sequences, do not allow us to trace their origins nor to follow the process of their integration into the host genome. Recent discoveries of virus-like sequences in plant genomes led us to set the objective of elucidating the origin of the repetitive sequences. Endogenous rice tungro bacilliform virus (RTBV)-like sequences (ERTBVs) have been found throughout the rice genome. Here, we reconstructed putative virus structures from RTBV-like sequences in the rice genome and characterized to understand evolutionary implication, integration manner and involvements of endogenous virus segments in the corresponding disease response.
\end{abstract}

Results: We have collected ERTBVs from the rice genomes. They contain rearranged structures and no intact ORFs. The identified ERTBV segments were shown to be phylogenetically divided into three clusters. For each phylogenetic cluster, we were able to make a consensus alignment for a circular virus-like structure carrying two complete ORFs. Comparisons of DNA and amino acid sequences suggested the closely relationship between ERTBV and RTBV. The Oryza AA-genome species vary in the ERTBV copy number. The species carrying low-copy-number of ERTBV segments have been reported to be extremely susceptible to RTBV. The DNA methylation state of the ERTBV sequences was correlated with their copy number in the genome.

Conclusions: These ERTBV segments are unlikely to have functional potential as a virus. However, these sequences facilitate to establish putative virus that provided information underlying virus integration and evolutionary relationship with existing virus. Comparison of ERTBV among the Oryza AA-genome species allowed us to speculate a possible role of endogenous virus segments against its related disease. 


\section{Background}

The virus-like sequences that have been found in plant genomes are divided into two groups of plant viruses, single-stranded DNA geminivirus and double-stranded DNA pararetroviruses. The geminivirus segments, including the viral replication origin and the adjacent $A L 1$ gene, have been found in the genomes of tobacco and its related species [1,2]. Pararetrovirus-like sequences have been reported in the petunia [3,4] banana [5-7] and tobacco genomes [8-10]. Compared to the intact virus sequences, most of the endogenous virus-like sequences were rearranged in the host genomes. Their rearranged structures suggested that illegitimate recombination may have occurred when putative virus progenitors integrated [11]. The endogenous viruses for banana streak virus (BSV) [6], tobacco vein-clearing virus (TVCV) [9] and petunia vein clearing-virus (PVCV) [4] could be activated as episomal viruses under certain conditions in the host plant, and appeared to have pathogenic potential. The integrations of these viruses were shown to have been relatively recent events and the copy numbers of the endogenous virus sequences were found to be very low. On the other hand, for tobacco endogenous pararetroviruses (TEPRVs), it was estimated that there are about 1000 segments in the tobacco genome [8], but the intact virus has not been identified so far, suggesting that the integration of TEPRVs was not a recent event. The finding of such endogenous virus sequences raises questions concerning 1) the integration process giving rise to endogenous virus sequences, 2) possible differences in the evolutionary rate between the virus and endogenous virus and 3 ) resistance potential as a result of endogenous virus integration.

In the rice genome, pararetrovirus-like sequences that are similar to rice tungro bacilliform virus (RTBV) have also been found [12-14]. In South and Southeast Asia, rice tungro bacilliform virus, which is transmitted by green leafhoppers, causes one of the most serious diseases of rice with the assistance of rice tungro spherical virus (RTSV) [15]. Kobayashi and Ikeda [16] reported that African rice species, Oryza glaberrima and O. barthii, showed much severer systemic necrosis compared to the other rice species present in South and Southeast Asia after inoculation of both RTBV and RTSV.

Here, we have characterized RTBV-like sequences in the Japonica (cv. Nipponbare) genome. These sequences, denoted endogenous RTBV-like sequences (ERTBVs), were highly rearranged and dispersed throughout the rice genome. Sequences of the putative viruses for ERTBV were reconstructed from the dispersed segment in the genome. Copy numbers of ERTBV segments are shown to vary among AA-genome Oryza species. Asian species have more ERTBV segments than the species originated from the other regions where RTBV is not distributed. The results obtained advance our understanding of the manner of integration of authentic pararetrovirus into the host genome, evolutionary implication of the integrated virus and possible involvement of endogenous virus segments in the corresponding disease resistance.

\section{Results \\ Identification of RTBV-like sequences in the rice genomes}

Previously, we found a repetitive sequence near the rice waxy gene, which is partially homologous to the rice tungro bacilliform virus (RTBV) genome [12,17]. A probe of this segment hybridized to about 30 bands in EcoRIdigested fragments from both Japonica and Indica genomic DNAs [12]. In the present study, we collected 29 RTBV-like sequences from the rice genome databases for Japonica (cv. Nipponbare). The segments collected here had ample length for further analyses. The segments of ERTBV were distributed throughout the rice genome. Structural differences among the collected ERTBV segments appeared to be due to rearrangements of the segments including deletions, insertions, inversions and duplications. None of the segments had the same structure as the virus or seemed likely to be active as virus. However, the similarities among the ERTBV segments were scored as more than $80 \%$ (described in detail in below), so that each homologous part in the ERTBV segments was easily recognized. Most of the ERTBV segments are flanked by AT-repeated sequences (Table 1), which might be involved in the integration mechanism.

\section{Assembling ERTBV segments}

We sorted out the 29 ERTBV segments using the sequences homologous to the RT gene, which is encoded in the end of ORF 3. Similarity analyses based on the RT gene grouped them into three clusters (Figure 1 and Table 1), suggesting the presence of three independent ERTBV sequence families. The discontinuity of the three clusters allows us to predict independent integration events for each of the ERTBVs into certain rice species genome(s). We then attempted reconstruction of the complete ERTBVs from the three clusters present in the phylogenetic tree. Approximately $7.5-\mathrm{kb}$ circular virus-like structures could be reconstituted by assembling common parts in individual ERTBVs. The assembled virus-like sequences, which are designated as ERTBV-A, -B and -C, encode potentially functional ORFs. The nucleotide similarities among ERTBVs range from $82 \%$ to $93 \%$, and therefore the segments are clearly distinguished in any of the clusters. Of the four ORFs in RTBV, ORF 3 and 4 correspond to ORF $y$ and $z$ of ERTBVs, but ORF 2 is absent from ERTBVs (Figure 2A). Nucleotide sequence of ORF 1 showed a $49 \%$ of homology to Region $\mathrm{x}$ of ERTBVs, while we failed to find ORF from the Region $\mathrm{x}$ sequences (Figure 2A). Pararetroviruses form a circular double-stranded DNA genome (Figure 2B), therefore, it is reasonable to believe 
Table I: Summary of the ERTBV structures in the rice genomes'.

\begin{tabular}{|c|c|c|c|c|c|c|c|c|c|c|}
\hline \multirow[t]{2}{*}{$\mathrm{Chr}^{2}$} & \multirow[t]{2}{*}{$\begin{array}{l}\text { Accession } \\
\text { Number }\end{array}$} & \multirow[t]{2}{*}{ 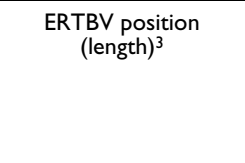 } & \multirow[t]{2}{*}{ Cluster ${ }^{4}$} & \multicolumn{5}{|c|}{ alignment of gene ${ }^{5}$} & \multicolumn{2}{|c|}{$\begin{array}{l}\text { AT-repeated } \\
\text { sequence }^{6}\end{array}$} \\
\hline & & & & Intergenic region & Region $\mathrm{x}$ & $\begin{array}{c}\text { ORF y (MPI } \\
\text { CP/PR) }\end{array}$ & $\begin{array}{c}\text { ORF y (RT/ } \\
\text { RH) }\end{array}$ & ORF z & 5 '-end & 3'-end \\
\hline & [Japonica] & & & & & & & & & \\
\hline \multirow[t]{2}{*}{1} & AP003338 & $31237-38745$ (7509) & $\mathrm{C}$ & $32277-31237$ & $38711-38217$ & $38259-348 \mid 4$ & $34534-33094$ & $33127-32278$ & $34(2)$ & $153(0)$ \\
\hline & & & & $38745-387 \mid 2$ & & & & & & \\
\hline \multirow[t]{5}{*}{2} & AP006160a & $128189-135399 a$ & $\mathrm{C}$ & $128189-128420^{a}$ & $\begin{array}{l}|2842|- \\
|289| 5^{a}\end{array}$ & $\begin{array}{l}\text { I28873- } \\
\text { | } 29447 \mathrm{a}\end{array}$ & $\begin{array}{l}\text { I34248- } \\
\text { I32808a }\end{array}$ & $\begin{array}{l}\text { |3284|- } \\
|3| 989 a\end{array}$ & $97(0)^{\mathrm{a}}$ & $12(0)^{\mathrm{b}}$ \\
\hline & AP004842 ${ }^{\mathrm{b}}$ & $1-7610^{b}(11686)$ & & $131988-131526^{a}$ & $7379-6885^{b}$ & $\begin{array}{l}|302| 2- \\
13|45|^{a}\end{array}$ & & & & \\
\hline & & & & $135399-1349 \mid 4^{a}$ & & $\begin{array}{l}\text { |349|3- } \\
134534^{a}\end{array}$ & & & & \\
\hline & & & & $7610-7380^{b}$ & & $5595-3136^{b}$ & & & & \\
\hline & & & & & & $6927-6352^{\mathrm{b}}$ & & & & \\
\hline \multirow[t]{7}{*}{4} & AL606628 & $4700 \mid-48868(1868)$ & B & - & - & $47001-47054$ & $47334-48768$ & $48756-48868$ & $16(0)$ & $45(391)$ \\
\hline & AL606618 & $82|65-88| 12$ (5948) & B & - & $88|12-8763|$ & $87673-84239$ & $83959-82532$ & $82544-82165$ & $13(678)$ & $156(48)$ \\
\hline & AL606592 & $36282-40413(4132)$ & B & $39437-40413$ & - & $36282-36894$ & $37|74-386| 4$ & $38602-39436$ & $65(0)$ & $101(17)$ \\
\hline & AL66297I & $104278-111739(7462)$ & $\mathrm{C}$ & $105283-104278$ & $\begin{array}{l}111720- \\
111226\end{array}$ & $\begin{array}{l}111268- \\
107823\end{array}$ & $\begin{array}{l}107543- \\
106102\end{array}$ & $\begin{array}{l}106135- \\
105284\end{array}$ & $65(727)$ & - \\
\hline & & & & $1|1739-||172|$ & & & & & & \\
\hline & AL607003 & $63290-71598$ (8309) & $A$ & $63406-64469$ & $64470-64882$ & $64846-68248$ & $68532-69972$ & $63290-63405$ & $52(68)$ & $\begin{array}{c}151 \\
(265)\end{array}$ \\
\hline & & & & $70794-71598$ & & & & $69939-70793$ & & \\
\hline \multirow[t]{2}{*}{5} & $\mathrm{ACl} 07085$ & $22244-29756(7513)$ & B & $22436-22244$ & $28859-28374$ & $284|6-2497|$ & $2469 \mid-23258$ & $23270-22437$ & $25(0)$ & $55(64)$ \\
\hline & & & & $29756-28860$ & & & & & & \\
\hline \multirow[t]{4}{*}{6} & AP002542 & $3396|-4| 438$ (7478) & B & $39087-38121$ & $38120-37636$ & $37678-34233$ & $39|2|-4054 \mid$ & $40529-41362$ & $216(2)$ & $252(1)$ \\
\hline & & & & $4|363-4| 438$ & & & & & & \\
\hline & AP006056 & $28996-33700(4705)$ & $\mathrm{C}$ & $29562-28996$ & - & $33700-32101$ & $3|82|-3038 \mid$ & $304 \mid 4-29563$ & $93(10)$ & $337(87)$ \\
\hline & AP004750 & $97242-104472(7231)$ & A & $98061-97242$ & $\begin{array}{l}104472- \\
103986\end{array}$ & $\begin{array}{l}104022- \\
100607\end{array}$ & $\begin{array}{c}100323- \\
98883\end{array}$ & $98916-98062$ & $39(178)$ & $52(694)$ \\
\hline \multirow[t]{5}{*}{7} & AP006163 & $118513-126010$ (7498) & C & $118513-118518$ & $\begin{array}{l}118519- \\
119013\end{array}$ & $\begin{array}{l}|1897|- \\
|224| 6\end{array}$ & $\begin{array}{l}122696- \\
124136\end{array}$ & $\begin{array}{l}124103- \\
124954\end{array}$ & $82(502)$ & $\begin{array}{c}224 \\
(I 29)\end{array}$ \\
\hline & & & & $124955-126010$ & & & & & & \\
\hline & AP0057I9 & $363-7932(7570)$ & $\mathrm{C}$ & $3278-2211$ & $2210-1716$ & $1758-363$ & $5526-4096$ & $4129-3279$ & $65(100)$ & $33(2)$ \\
\hline & & & & & & $7932-5806$ & & & & \\
\hline & AP004348 & I7568-24897 (7330) & $A$ & $185 \mid 3-17568$ & $24897-24437$ & $24473-21059$ & $20775-19335$ & $19368-18514$ & $96(100)$ & $37(20)$ \\
\hline \multirow[t]{9}{*}{8} & AP005I64 & $17 \mid 654-179236(7583)$ & C & $173775-174838$ & $\begin{array}{c}174839- \\
175333\end{array}$ & $\begin{array}{l}|7529|- \\
\mid 78760\end{array}$ & $\begin{array}{l}171654- \\
172956\end{array}$ & $\begin{array}{l}172923- \\
173774\end{array}$ & $52(284)$ & $274(11)$ \\
\hline & & & & & & & $\begin{array}{l}17907 \mid- \\
179236\end{array}$ & & & \\
\hline & AP003883 & II7668-I25I43 (7476) & C & II7668-|17743 & $\begin{array}{l}\text { I I7744- } \\
\text { I I } 8238\end{array}$ & $\begin{array}{l}118196- \\
12164 \mid\end{array}$ & $\begin{array}{l}121921- \\
|2336|\end{array}$ & $\begin{array}{l}123328- \\
124179\end{array}$ & $54(6 \mid 2)$ & $41(16)$ \\
\hline & & & & $|24| 80-125 \mid 43$ & & & & & & \\
\hline & AP003914 & 22973-2520I (2229) & $A$ & - & - & - & $23074-245 \mid 4$ & $2448 I-2520 I$ & $373(14)$ & $1136(0)$ \\
\hline & AP00530I & $34330-41566$ (7237) & $A$ & $34330-34741$ & $34742-35228$ & $35|92-386| 1$ & $38895-403 \mid 4$ & $40281-41135$ & $153(14)$ & $34(23)$ \\
\hline & & & & $4|136-4| 566$ & & & & & & \\
\hline & AP005I59 & $88879-97300$ (8422) & B & $88879-89828$ & $89829-90315$ & $90273-93716$ & $93996-95435$ & $95423-96256$ & $179(0)$ & $34(19)$ \\
\hline & & & & $96257-97300$ & & & & & & \\
\hline \multirow[t]{3}{*}{9} & AP005424 & II998-18576 (6579) & $\mathrm{C}$ & $18576-17867$ & II998-12492 & $12450-15849$ & $16129-17569$ & $17536-17833$ & $57(10)$ & $95(225)$ \\
\hline & AP005860 & 50709-5828I (7573) & $A$ & $50709-50806$ & $50807-51295$ & $51259-54579$ & $54863-56304$ & $5627|-57| 24$ & $218(0)$ & $8(3)$ \\
\hline & & & & $57|25-5828|$ & & & & & & \\
\hline \multirow[t]{5}{*}{10} & $\mathrm{ACI} 19147$ & $89355-102382(13028)$ & B & $90235-89355$ & $\begin{array}{c}101319 \\
100834\end{array}$ & $99260-96143$ & $95863-94424$ & $94436-93603$ & $71(0)$ & $183(68)$ \\
\hline & & & & $93602-93432$ & & $\begin{array}{l}100876- \\
100548\end{array}$ & & & & \\
\hline & & & & $102382-101320$ & & & & & & \\
\hline & AC027660 & $24299-3 I 769$ (747I) & $A$ & $29370-28257$ & $28256-27768$ & $27804-24390$ & $31632-30192$ & $30225-2937 \mid$ & - & $28(520)$ \\
\hline & AC069300 & $89901-96619(6719)$ & $A$ & $90209-89901$ & $96619-96133$ & $96169-92755$ & $92471-91031$ & $91064-90210$ & $21(162)$ & $21(688)$ \\
\hline \multirow[t]{2}{*}{ II } & $\mathrm{ACl} 35957$ & $69527-8|25|(11725)$ & $A$ & $73392-74286$ & $8|25|-80765$ & $69527-70846$ & $71130-72570$ & 72537-73391 & $368(619)$ & - \\
\hline & & & & $75398-74475$ & & $80801-77387$ & & $75444-75410$ & & \\
\hline \multirow[t]{2}{*}{12} & AL7I3945 & $4599 \mid-49426$ (3436) & B & $47029-45991$ & - & - & $4929|-4785|$ & $47863-47030$ & $55(I)$ & $261(9)$ \\
\hline & AL73 I 743 & $|423|-\mid 8608$ (4378) & B & $17596-18608$ & |4768-|4283 & $|4325-| 423 \mid$ & $15333-16774$ & $16762-17595$ & - & $44(40)$ \\
\hline
\end{tabular}


Table I: Summary of the ERTBV structures in the rice genomes'. (Continued)

\begin{tabular}{|c|c|c|c|c|c|c|c|c|c|c|}
\hline & \multirow[b]{2}{*}{ AL928780 } & \multirow[b]{2}{*}{$103|87-| \mid 0757$ (757|) } & \multirow[b]{2}{*}{ A } & & \multicolumn{3}{|c|}{$|479|-15053$} & \multirow[b]{2}{*}{$\begin{array}{l}109072- \\
109926\end{array}$} & \multirow[b]{2}{*}{$44(25)$} & \multirow[b]{2}{*}{$25(32)$} \\
\hline & & & & $103187-103406$ & $\begin{array}{l}103407- \\
103893\end{array}$ & $\begin{array}{l}103857- \\
107273\end{array}$ & $\begin{array}{l}107665- \\
109105\end{array}$ & & & \\
\hline & & & & |09927-|10757 & & & & & & \\
\hline & $\begin{array}{l}\text { AL928749 } \\
\text { [Indica] }\end{array}$ & $6275-11538$ (5264) & A & $7149-6275$ & - & $11538-9695$ & $94|I-797|$ & $8004-7 \mid 50$ & $479(127)$ & $624(0)$ \\
\hline 4 & $A B|2459|$ & $554-4677(4 \mid 24)$ & B & $3709-4677$ & - & $554-1166$ & 1446-2886 & 2874-3708 & $43(0)$ & $105(26)$ \\
\hline ND & $A B \mid 24592$ & $8867-\mid 4510(5644)$ & $\mathrm{C}$ & $10990-12051$ & $12052-12546$ & $12504-14510$ & $8867-10171$ & $10138-10989$ & $64(273)$ & $\begin{array}{c}\text { unknow } \\
n\end{array}$ \\
\hline ND & $A B \mid 24593$ & $|58-59| 4(5757)$ & $\mathrm{C}$ & $4214-5914$ & - & $158-1677$ & $1957-3397$ & $3364-4213$ & $157(0)$ & $62(2)$ \\
\hline
\end{tabular}

I The sequences were mined from Japonica database or investigated from phage clones isolated from Indica (IR36) genomic library.

2 Chromosome no. on which the ERTBV segment resides.

3 Nucleotide positions of ERTBV in the registered genomic clone. Parenthesis indicates a length of ERTBV sequence.

4 Clusters into which the individual ERTBV sequences were phylogenetically grouped.

5 The region belongs to the part of ERTBV, and their nucleotide positions in the clone registered in the database.

6 The numbers indicate repetition times of AT at both the ends of ERTBV, and parenthesis indicates distance (bP) from the ERTBV.

$a$ and $b$ These clones contain the identical ERTBV, but both the clones ended within the ERTBV sequence.

that the authentic ERTBV viruses had a similar structure. It seems that the integration of ERTBVs did not occur randomly since more than a half of the ERTBV ends connected with rice genomic DNA were in the putative intergenic region (IGR) (Figure 2B). In addition, the other common junctions are found in the middle of ORF y (Figure. $2 \mathrm{~B}$ ), which corresponds to the location of the discontinuities in the open circular form of RTBV [18]. These structures may indicate that the integration process occurred after the reverse transcription of the virus genome.

The longest ORF in RTBV, ORF 3 encodes the movement protein $(\mathrm{MP})$, coat protein $(\mathrm{CP})$, asparatic protease (PR), RT and RNase $\mathrm{H}(\mathrm{RH})$ in the single polycistronic mRNA [19]. ORF 3 mostly parallels ORF y in ERTBV-A, -B and -C. Similarities within these nucleotide sequences between the RTBV and ERTBVs were around 50\%. The amino acid identity of the genes in ORF 3 ranged from $63 \%$ for RT/RH to $40 \%$ for PR genes. With respect to RT and RH genes in ORF 3, all characteristic motifs and invariant amino acids for individual genes were preserved in the corresponding ORF in each consensus ERTBV (Figure 3). Therefore, the putative genes in consensus ERTBVs potentially encode proteins comparable to those in RTBV.

To evaluate the genetic relationship of ERTBVs and RTBV, RT amino acid sequences from the viruses belonging to Caulimoviridae, were compared. Using the PHYLIP package program [20], the phylogenetic tree was constructed for 14 kinds of viruses in Caulimoviridae (Figure 4). RTBV and ERTBV-A -B and -C were found to be most closely located in the RT peptides dendrogram among the Caulimoviridae viruses. These results strongly suggest that ERTBVs are virus in origin and are closely related with RTBV.
No sequences exactly matching RTBV per se were found in the databases for Japonica cV. Nipponbare. We conducted Southern hybridization analysis to see whether RTBVhomologous sequences are present in 14 lines from Oryza AA-genome species (Table 1). The hybridization patterns probed with RTBV sequence resulted in faint and indistinct bands (data not shown).

\section{Periods of integration of ERTBV segments into the rice genome}

To investigate the periods of integration of ERTBV, we attempted to obtain ERTBV sequences from an Indica variety (cv. IR36) using the RTBV-like sequence near the waxy locus as a probe. We thereby isolated three clones carrying ERTBV-homologous sequences (Table 1). Indica clone, AB124591, was found to have the same ERTBV sequence as that found in Nipponbare accession AL606592 (Table 1 ), indicating that the ERTBV integration events occurred before the Japonica-Indica differentiation. The other two Indica clones do not correspond with any ERTBV segments from Nipponbare.

Except for the sequences examined here, we could not find any other RTBV-like sequences in database searches using RTBV nor each of ERTBVs sequences as queries. Therefore, a fourth cluster of the RTBV-like sequences is unlikely to be present. The integration of ERTBV or its derived segments after the differentiation of Japonica and Indica cultivars thus seems to have not occurred.

\section{Distribution of ERTBVs in the Oryza AA-genome species}

To test whether other Oryza species contain ERTBV in their genomes, Southern blotting experiments were performed with 14 lines of the Oryza AA-genome species. A PCR fragment of the 7.4-kb ERTBV sequence from chromosome 10 was prepared as a probe, and Figure 5 shows the discrete bands and varying copy numbers revealed by the 


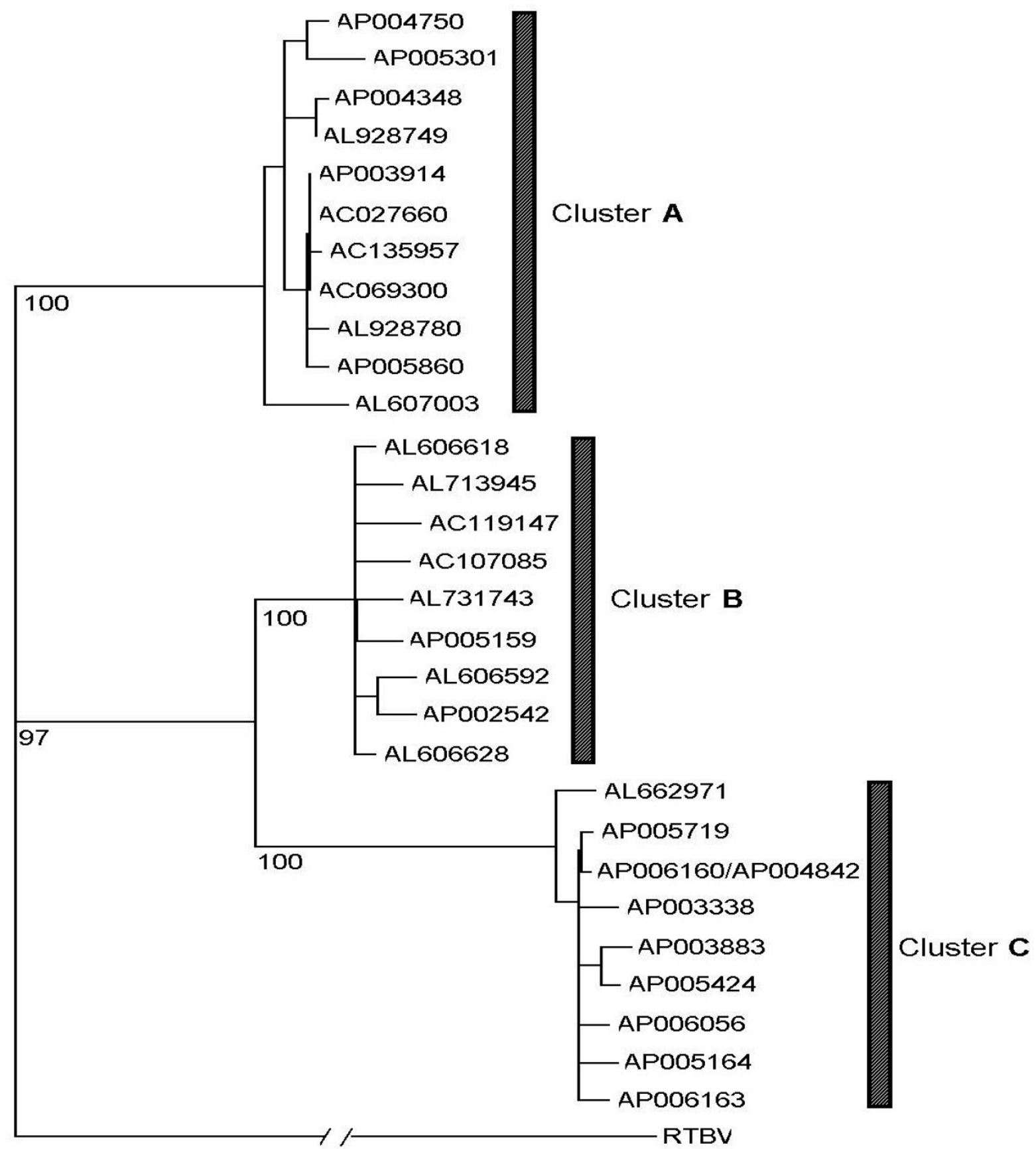

0.01 substitutions / site

\section{Figure I}

The phylogenetic tree based on reverse transcriptase (RT) gene of 29 ERTBV segments and RTBV. These ERTBV were collected from the rice genome database (Table I). The nucleotide sequences were aligned using the CLUSTAL W program [35] from the DNA Data Bank Japan (DDBJ). The method detailed of construction of the tree was described in the text. These sequences were fallen into three clusters, ERTBV-A, -B and -C. Numbers above the nodes are bootstrap support based on 100 bootstrap replicates for all branches were resolved on the strict consensus tree. 


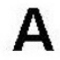

RTBV (8.0 kb)

ERTBV (7.5 kb)
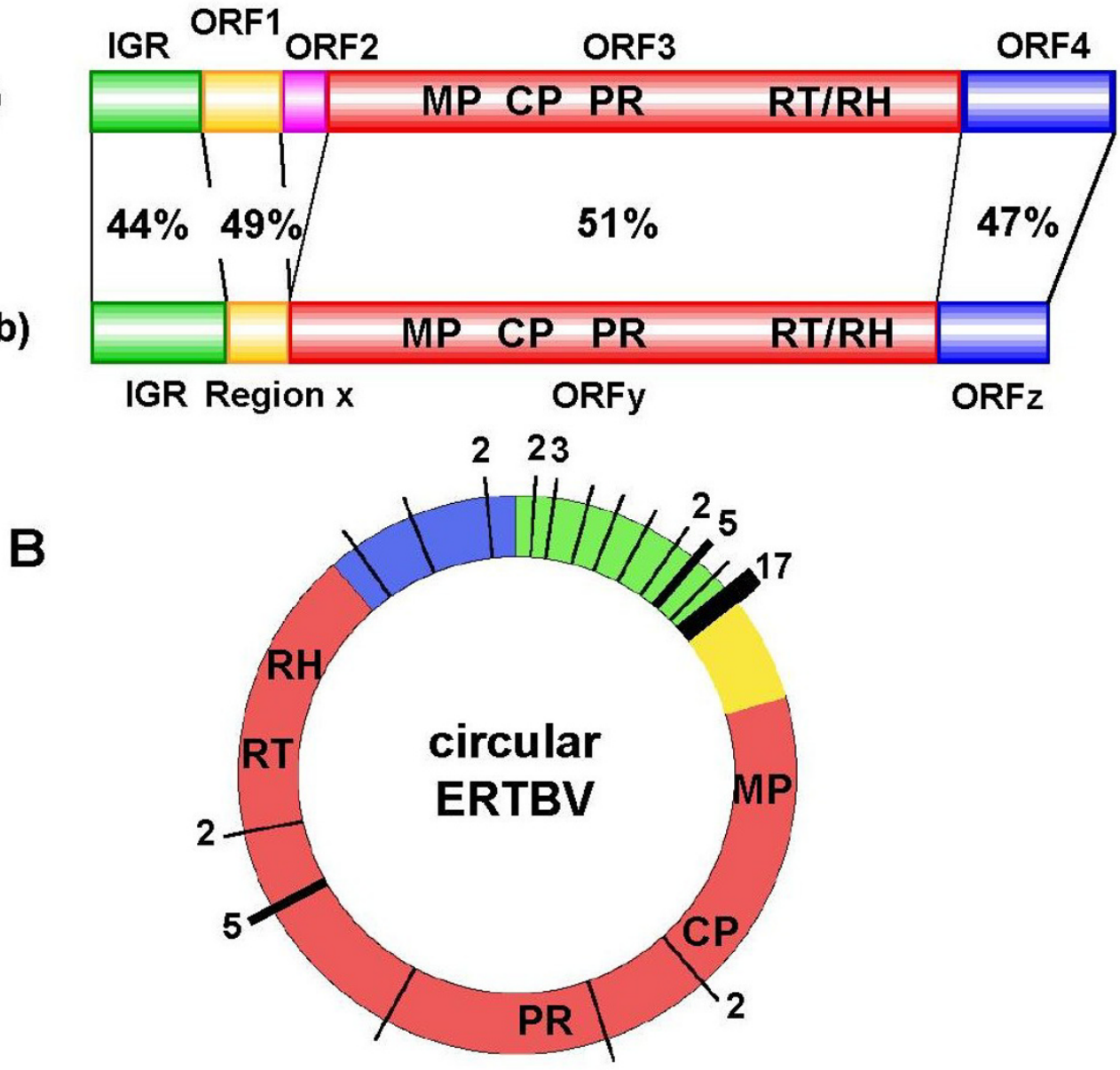

Figure 2

Deduced virus form of ERTBV that was assembled from the rice genomic sequences. A: Comparison of the assembled ERTBV and RTBV. Percentages indicate the nucleotide similarity of each of the corresponding segments or ORFs between ERTBV and RTBV. ERTBV lacks ORF I and 2. The assembled sequences designated as ERTBV-A, -B and -C have 7526 bp, 7496 bp and 7499 bp in length, respectively. Their assembled sequences consist of intergenic region (IGR) (A: I-I I I4; II I4 bp, B: I-I066; I066 bp: C: I-I063; 1063 bp), Region x (A: I I I5-I600; 486 bp, B: 1067-I552; 486 bp, C: I064-I558; 495 bp), ORF y (A: I570-6702; 5133 bp, B: I5I9-6672; 5 I54 bp; C: I525-6678; 5 I54 bp) and ORF z (A: 6702-7523; 822 bp, B: 6672-7493; 822 bp, C: 6678-7496; 819 bp). Identical organizations of ORFs and their orders were observed in their structures. The nucleotide sequence for Region $x$ corresponds with ORF I, but ATGs for initiation codon were not present. ORF 3 contains movement protein (MP), coat protein (CP), asparatic protease (PR) and RNase H (RT/RH) [19]. B: Schematic representation of the junction sites of the ERTBV segments adjoining the rice genomic sequence. The junctions are indicated by vertical bars on the circular virus form of ERTBV. The figure shows the number of junctions of all the examined segments referred to Table I. The different colors in the circle correspond to the above-mentioned segments. The junctions are concentrated in the IGR, which contains the transcriptional initiation and terminal overhanging segments.

hybridization patterns. Each accession or cultivar of $O$. sativa and $O$. rufipogon (lanes 1-8) has about 50 bands, some of which showed common sizes among the lines. An Australian rice (O. meridionalis) and two O. longistaminata accessions showed middle-copy numbers (approximately 10-20) of the ERTBV segments. In O. glaberrima, $O$. barthii and O. glumaepatula accessions, only a few bands hybridized to ERTBV; this may also be caused by divergence of the ERTBV sequence and not only due to lower copy numbers of the sequence. Especially in These three species derived from Africa and Latin America were genetically distinct from Asian rice species, but another African rice species, $O$. longistaminata, was considered to 


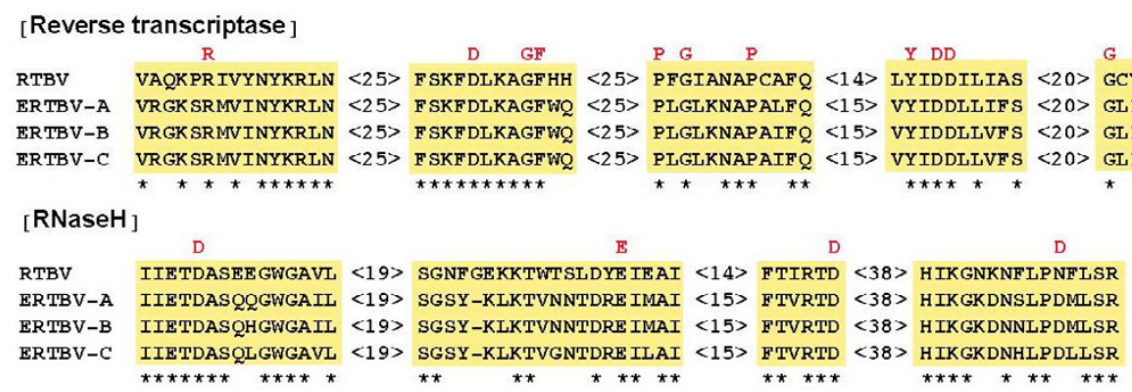

\section{Figure 3}

Amino acids sequence alignments for RT and RH domains of RTBV and the assembled ERTBVs. The alignments were performed with the CLUSTAL W program and the conserved motifs are shown encompassed by yellow. The numbers after each motif indicate the numbers of the amino acids, which are not conserved. Conserved amino acid residues are marked with an asterisk. Invariant amino acids are highlighted in red above the sequences.

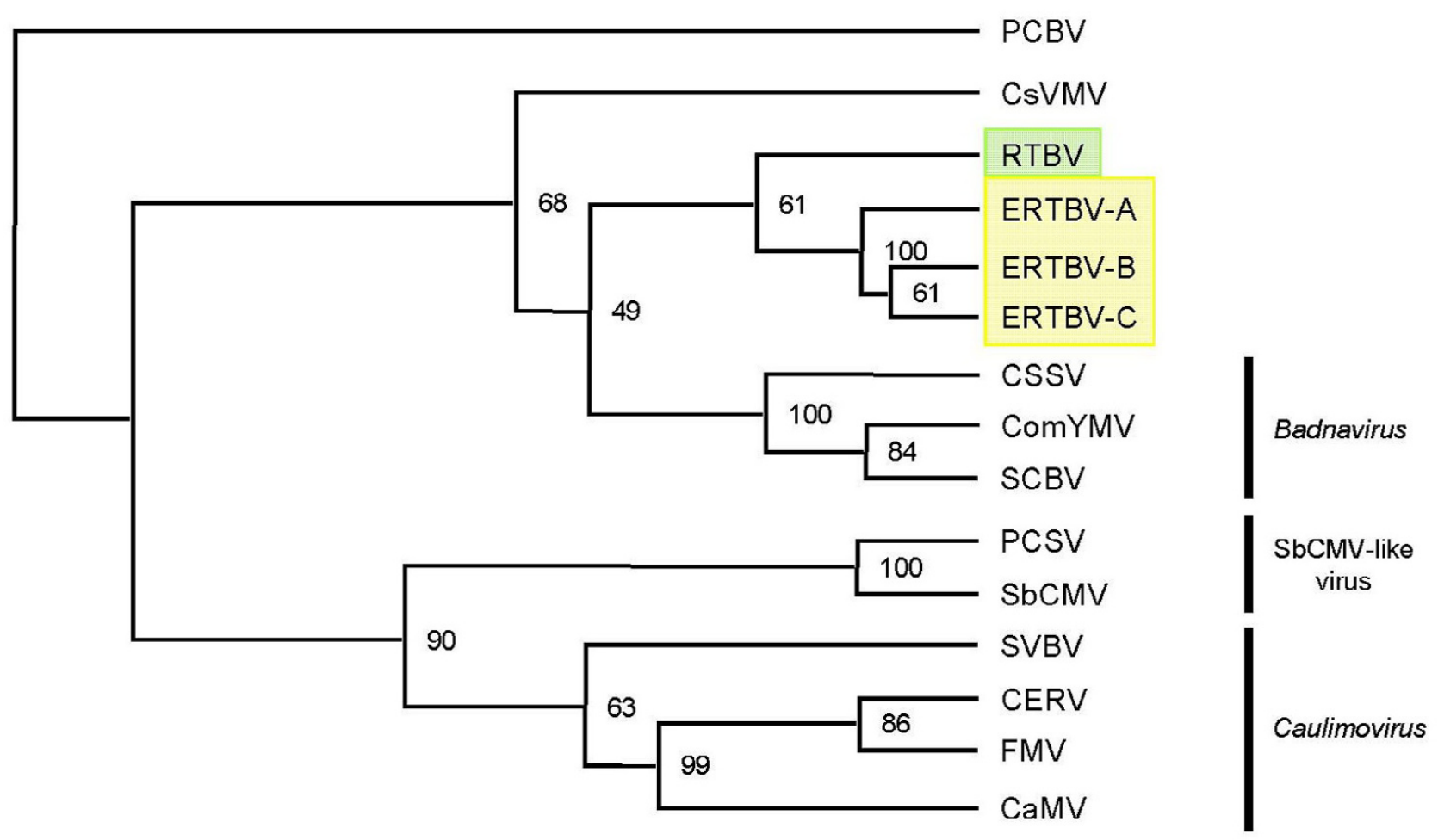

Figure 4

Neighbor-joining dendrogram of putative RT amino acid sequence relationships among species of the different genera of the Caulimoviridae family. The dendrogram was bootstrapped 100 times (percent scores shown at nodes) and rooted on a random sequence. 


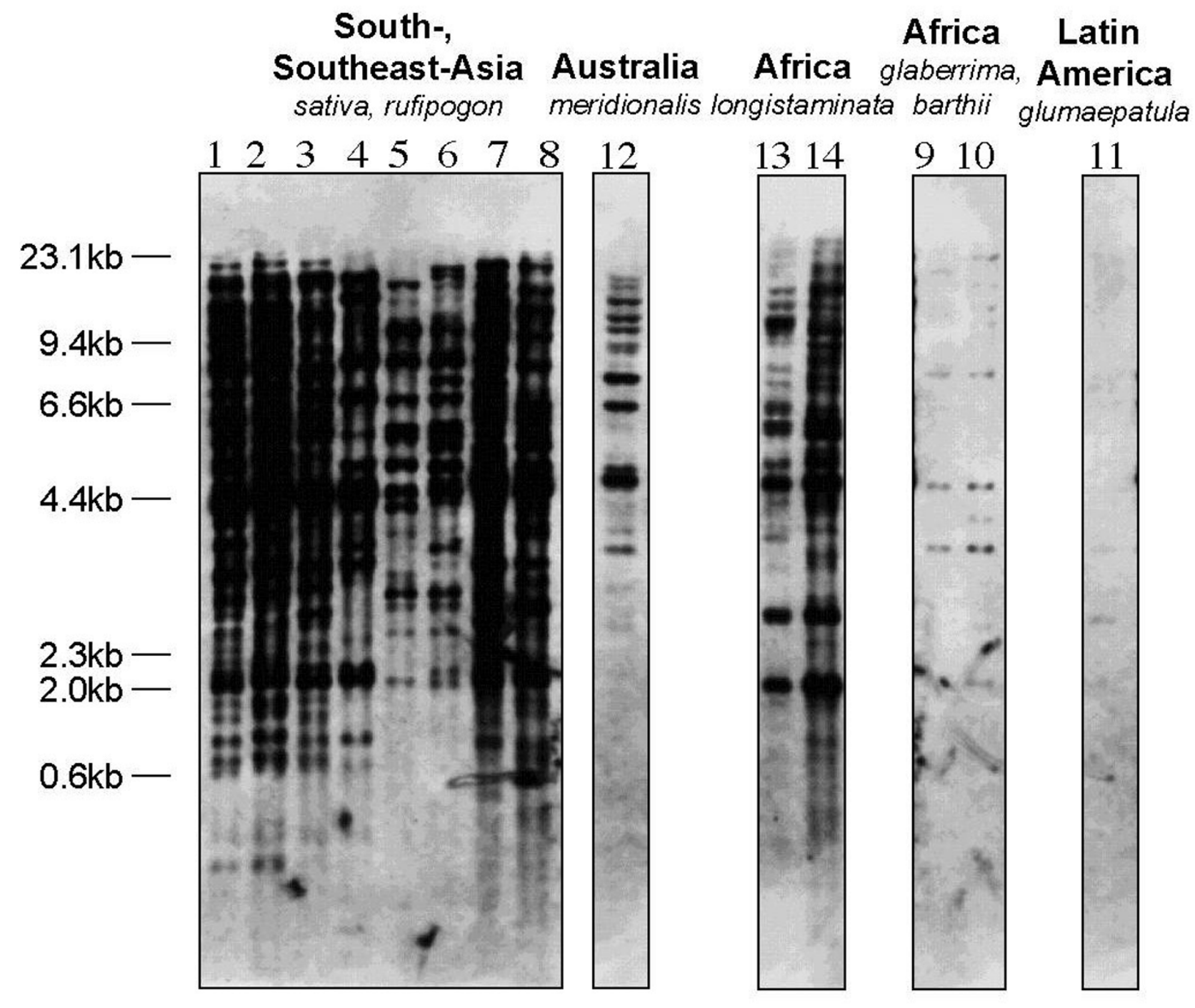

Figure 5

Southern blotting patterns for the genomic DNAs from 14 Oryza lines probed with 7.4-kb ERTBV fragment. The numbers above the blots correspond to the numbers of the materials (Table 2). The regions are the origins of the materials. Some accessions/lines of $O$. sativa, $O$. rufipogon and $O$. longistaminata are being used as the sources of resistance against tungro disease.

have undergone introgression with Asian species [21]. Africa and Latin America are regionally isolated from rice tungro disease.

\section{Methylation of ERTBV in Oryza AA-genome species}

Since high-copy-number sequences generally tend to have a heavier methylation state than low-copy-number sequences, we investigated the methylation state of ERTBVs in several Oryza species with various copy numbers. The methylation states were analyzed by Southern blotting method using a methylation-sensitive enzyme, HpaII, and a partially methylation-sensitive isoschizomer, MspI. The 7.4-kb probe was employed to examine the methylation states of the ERTBV in the Oryza AA-genome 
species. The blotting patterns of O. sativa (Shimokita), O. rufipogon (W1954), O. longistaminata (W1034), O. meridionalis (W1625), O. barthii (W1592), O. glumaepatula (W1185) showed differences of methylation state depending on the ERTBV copy number (Figure 6). In the high-copy-number species, $O$. sativa and $O$. rufipogon, the MspI and HpaII digests of DNA clearly showed different digestion patterns, and in particular, most of the small bands in the MspI digests were not observed in the HpaII digests, indicating that these ERTBV sequences were considerably methylated. Although the results of blotting for the middle-copy-number species, $O$. longistaminata and $O$. meridionalis, also showed the presence of methylcytosine within their ERTBV sequences, some bands in the MspI digests were shared with the HpaII digests. Preferential digestion of DNA from the low-copy-number species, $O$. barthii and O. glumaepatula, compared to DNA from the other species was observed. The above results indicate that the copy number of the ERTBV sequences in the Oryza genomes is correlated with the methylation level. A chloroplast DNA fragment [22] was used as a control probe to confirm the completeness of digestions (data not shown).

\section{Discussion \\ Completion of ERTBV via integration of the virus}

Our data suggest that the putative virus for ERTBVs has been integrated into the Oryza genomes at least three times. These putative viruses are thought to be closely related to RTBV and to form circular double-stranded DNA. Cleavage of circular DNA molecules or open circular forms should be required for integration of the infecting virus. One of the preferential cleavage sites of ERTBV was mapped within a putative promoter segment of the authentic ERTBV sequence. Integrated sequences of TPVL in tobacco [8] and hepatitis B (hepadna) virus in human liver [23] were also found to have preferred junctions with their host genomes at a similar region to that seen in ERTBV. Jakowitsch et al. [8] proposed that the open circular form of the virus during the process of replication was involved in integration, and the free ends of the virus DNA molecule might contribute to integration or recombination. The ends of the ERTBV segments likely correspond with IGR and the putative discontinuities of RTBV (Figure 2B), which possibly functions in transcription and replication initiation or in the priming of DNA strand synthesis [18]. This fact accords with Jakowitschs' idea that the preferential integration occurred while the virus was in the process of replication (Figure 7). In addition to the preferred sites for integration within the virus DNA, we found that $93 \%$ of the ERTBV ends were flanked by ATrepeated sequences. This high probability of the presence of AT-repeated sequences adjoining ERTBV led us to postulate that the AT tracks have facilitated or are associated with integration of the virus DNA into the host genome (Figure 7). Transgenes introduced by particle bombard- ment into the Arabidopsis genome were preferentially delivered to AT-rich scaffold/matrix-attached region (S/ MAR)-like sequences $[24,25]$. SINE integration sites in the Brassica genome show strong affinity for S/MAR-like sequences [26]. Similar processes accounting for these two instances might also function in the case of integration of the virus for ERTBV. Our data alone, however, are unable to distinguish between whether ERTBV integrated into the AT-repeat sequences or whether ERTBV accompanied the AT-repeat sequences in their integration (Figure 7).

\section{Relationship between ERTBV and RTBV}

Although the genomes of ERTBV and RTBV are structurally similar, particularly in the longest ORF, some regions are markedly different. Phylogenetically, both are apparently closely related viruses. One important question is whether or not ERTBV is a cognate of RTBV. ERTBVs existed in the Oryza AA-genome species before differentiation of Japonica and Indica. Considering this evolutionary period, two possible relationships of RTBV and ERTBV might be predicted: one is that the virus that was to become ERTBV was a direct progenitor of RTBV, and the other is that both were differentially branched from a common ancestral virus. Because the evolution of virus genomes is generally much faster than that of plant genomes, we cannot compare them equivalently. In fact, rapid evolution of RTBV was inferred from high level of genetic diversity of RTBV field isolates [27]. Even in a single field in the Philippines, more than one RTBV isolate could be observed, and the genotype changes year by year. Comparison of the sequences of several different isolates revealed evidence for incidences of nucleotide substitution, insertion/deletion and recombination occurred during differentiation of RTBV isolates [28]. Particularly, it was suggested that recombination had played a role in the evolution of RTBV [29]. If ERTBV is a direct progenitor of RTBV, recombination events might have contributed as a driving force to establish the present RTBV form. The longest ORF (ORF 3) of RTBV is functionally essential [30] and is thought to have been conserved since ERTBVs were present as viruses, but the other less homologous segments might have gradually undergone substitution by recombination. If RTBV was derived from the virus that became ERTBV, estimation of the nucleotide substitution rate of the genes common to RTBV and ERTBV would allow us to compare the evolutionary rates of a plant genome and a plant virus. By such a comparison, we estimated the virus evolution ranged from 30 to 140 times faster than that of the host genome. The faster evolution of a virus was thus substantiated for the first time in plants if the virus for ERTBV was in fact the progenitor of RTBV. The different evolutionary rates are dependent on the virus genes; that is, the slow evolution might reflect the functional conservation of the gene. 


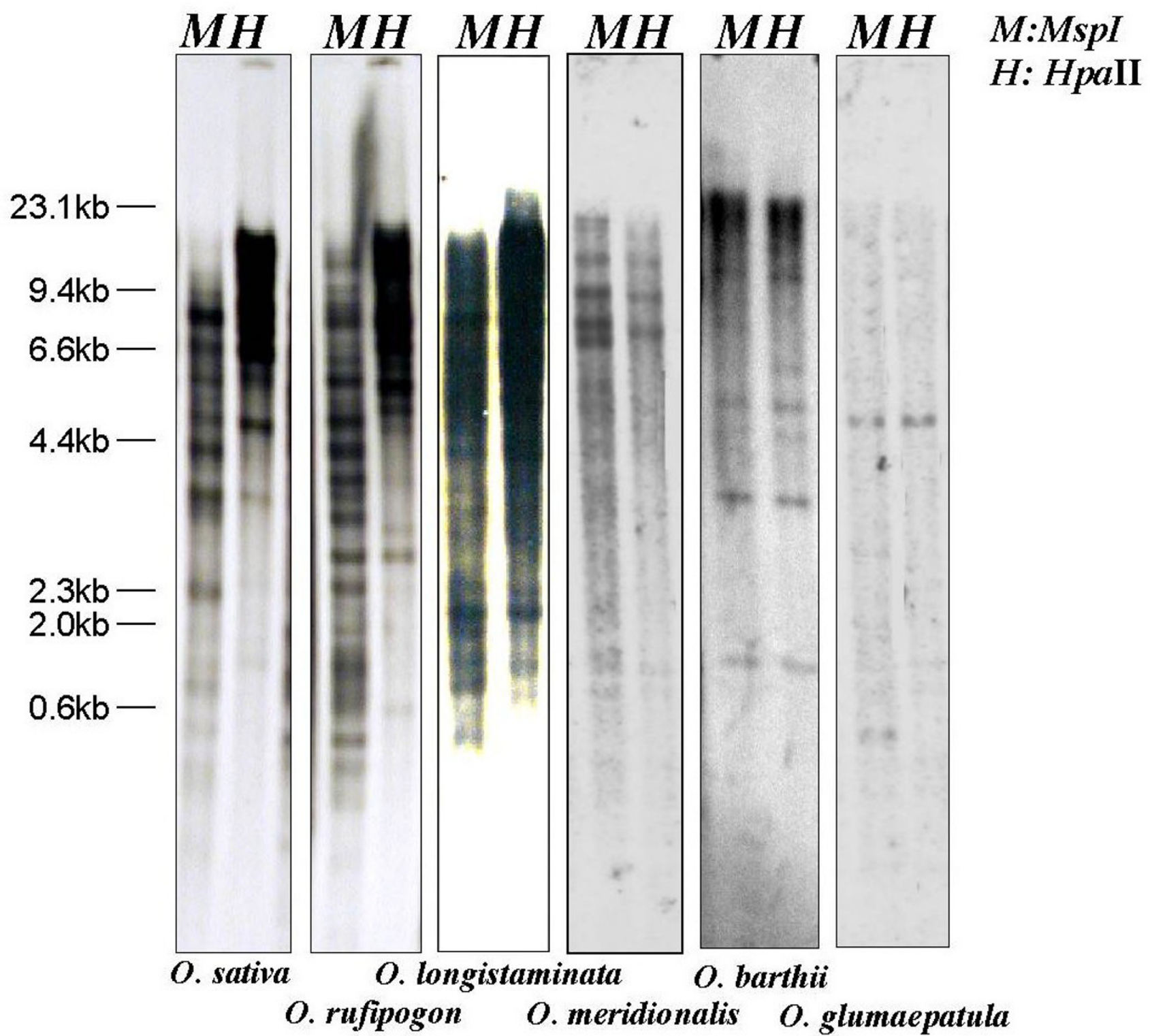

\section{Figure 6}

Methylation state of ERTBV in the genomic DNAs from the Oryza AA-genome species. Each genomic DNA was digested with Mspl $(\mathrm{M})$ or Hpall $(\mathrm{H})$ as described in Materials and Methods. Differential hybridization patterns between the Mspl and Hpall digests observed in $O$. sativa and $O$. rufipogon show heavier methylation compared to the others, and 0 . longistaminata indicates possession of methylated ERTBV segments in the genome.

In the other case, in which RTBV and the virus for ERTBV are phylogenetically located on different branches, the progeny of the virus corresponding to ERTBV might have vanished or may be hidden in a small population. Even though RTBV is not in the case a direct progeny of the virus corresponding to ERTBV, their structural similarity and parallel distribution lead us to consider their common ancestral origin. 
Virus in the process of reverse transcription or transcription

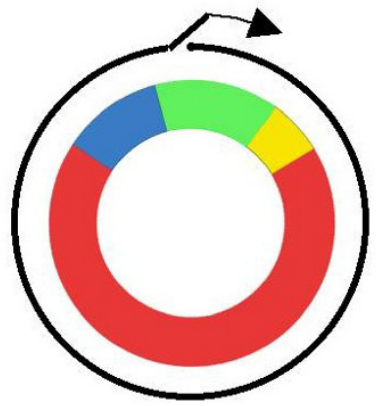

AT repeat attached to virus genome Targeted to AT repeat

ATATATATATAT ATATATATATAT Rice genome ATATATATATATATATATATATAT
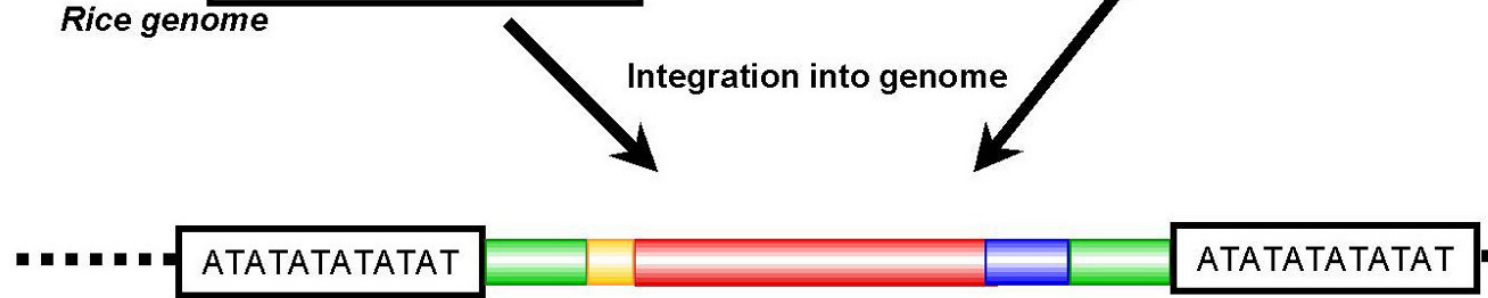

\section{Figure 7}

Two hypothetical processes for the integration of the putative virus for ERTBV into the rice genome. DNA strands after the reverse transcription step of the virus were targeted to AT-repeat sequences (left), or AT-repeat sequences became attached to the virus segments during the process of the reverse transcription and the complex was integrated into the rice genome (right).

\section{Correlation between rice tungro disease and ERTBV}

Plant virus-like sequences have been found in several plant genomes such as banana, tobacco and petunia $[11,31]$. So far, no association between virus disease and endogenous virus sequences has been reported [32]. Kobayashi and Ikeda [16] reported that O. glaberrima and $O$. barthii showed severe systemic necrosis within 4 weeks after infection of RTBV and rice tungro spherical virus (RTSV). O. longistaminata, which possesses ERTBV fragments in its genome, showed disease symptoms like those of the Asian species, and some of the accessions were utilized for obtaining the resistance gene [29]. Interestingly, this species originated from Africa where RTBV is not distributed. The fact led us to suppose that there is a correlation between presence or absence of ERTBV in the genome and the degree of RTBV susceptibility. The species, which have a low-copy-number of ERTBV tend to be vulnerable to the rice tungro disease caused by both RTBV and RTSV. The methylation of ERTBV appeared to be positively related in the copy number in the genome. Based on a study on the endogenous virus sequences (EPRV) in tobacco, Mette et al. [33] proposed a model in which methylation dependent on the copy number of endogenous virus sequences may induce episomal viral methylation through a homology-dependent process involving DNA-DNA or RNA-DNA interaction. The phenomenon observed here fits their model. The copy number of EPRV in the tobacco genome is 10 times as high as that of ERTBV in the rice genome. Our results demonstrated that about 50 copies of endogenous elements are sufficient to induce methylation in the genome. If we ever find the rice germ lines that have incorporated sequences more similar to those of RTBV, as well as ERTBV in germ lines, those would be exploited as valuable sources of stronger resistance against the rice tungro disease.

\section{Conclusions}

The rice genome contains more than 30 of RTBV-like sequence (ERTBVs) which were unlikely to have functional potential as a virus, while we were able to 
Table 2: Plant materials used.

\begin{tabular}{|c|c|c|c|}
\hline Sample & Species & Cultivar or accession & Remarks \\
\hline I & O. sativa & Shimokita & Japonica from Japan \\
\hline 2 & O. sativa & T65wx & $\begin{array}{l}\text { Near-isogenic line of Taichung } 65 \text { with wx from } \\
\text { Kinoshitamochi }(\mathrm{BC} / 2)\end{array}$ \\
\hline 3 & O. sativa & 221 & Javanica type from Indonesia \\
\hline 4 & O. sativa & PTB।O & Indica type from India \\
\hline 5 & O. rufipogon & W107 & Annual type from India \\
\hline 6 & O. rufipogon & WI20 & Perennial type from India \\
\hline 7 & O. rufipogon & WI7I7 & Perennial type from China (through IRRI) \\
\hline 8 & O. rufipogon & WI7I8 & Perennial type from China (through IRRI) \\
\hline 9 & O. glaberrima & W025 & From Guinea \\
\hline 10 & O. barthii & WI592 & From Cameroon \\
\hline 11 & O. glumaepatula & WII85 & From Surinam \\
\hline 12 & O. meridionalis & W1625 & From Australia \\
\hline 13 & O. longistaminata & W1034 & From Nigeria \\
\hline 14 & O. longistaminata & WI572 & From Nigeria \\
\hline
\end{tabular}

assemble putative virus forms from these sequences. The phylogenetic analysis showed that at least three times integrations of authentic ERTBVs occurred during Oryza speciation. ERTBV integrations likely occurred when the virus was in the replication process, and were preferentially targeted to AT-repeat sequences. The closely relationship between ERTBV and RTBV were proven by comparisons of the DNA and amino acid sequences. The Oryza AA-genome species originated from RTBV-distributed regions appeared to contain higher copy numbers of ERTBV segments. The methylation state of the ERTBV sequences was correlated with their copy number in the genome. The results obtained allowed us to speculate a possible relationship between RTBV disease resistance and the copy number and/or DNA methylation of ERTBV in the Oryza AA-genome species.

\section{Methods}

\section{ERTBV sequences from Japonica}

Sequences of ERTBV in Japonica (cv. Nipponbare) were mined with rice blast search queries [34] against the rice genome sequences that had been registered as of June 2003. Twenty-nine ERTBV sequences were found in the following Japonica genomic database (Table 1).

\section{ERTBV sequences from Indica}

We attempted to search for ERTBV sequences in the Indica (cv. 93-11) genome database, however, the homologous sequences found through the search had insufficient length for designation as ERTBV segments. Indica ERTBV sequences were isolated from the EMBL 3 genomic library constructed with IR36 strain (FL1041j), which was purchased from Clontech (Palo Alto, California). For screening, a 3.5-kb ERTBV fragment about 50-kb upstream of the waxy locus was used as probe [17]. Three clones carrying an ERTBV-containing segment of more than $4 \mathrm{~kb}$ were selected. Nucleotide analysis was performed with using a d-Rhodamine Terminator Cycle Sequencing Ready Reaction-Sequencing Kit (Applied Biosystems) and an ABI377 Automated DNA Sequencer (Applied Biosystems).

\section{Construction of phylogenetic trees}

The nucleotide sequences and amino acids sequences inferred from the reverse transcriptase (RT) gene were aligned using the CLUSTAL W program [35] from the DNA Data Bank Japan (DDBJ). We calculated the pairwise nucleotide divergence $(\mathrm{K})$ between 30 independent ERTBV sequences (including RTBV) based on Kimura's two-parameter method [36] without taking synonymous and nonsynonymous changes into account. We constructed a neighbor-joining (NJ) tree based on these estimates [37]. The tree was drawn using PAUP*4.0 [38]. The consensus maximum parsimony and $\mathrm{NJ}$ trees based on amino acid sequences for RT in 14 viruses including ERTBV-A, $-\mathrm{B}$ and $-\mathrm{C}$ were calculated using programs from the PHYLIP package [20]. The minimum evolution tree was calculated by the implementation of PAUP software in the GCG package.

\section{Southern hybridization}

Total genomic DNA was isolated from 7 Oryza AAgenome species including 14 strains (Table 2). EcoRIdigested DNA was separated by $0.7 \%$ agarose gel electrophoresis. The resultant DNA was transferred to nylon membranes (Pall: Biodyne B), and hybridized using the Alk Phos Direct Southern hybridization kit (Amersham Life Science). For the probe, nearly the full length of the 7.4-kb ERTBV fragment (located on chromosome 10, BAC clone accession no. AC069300) was amplified by PCR 
with the primer combination of 5'GAACTACAACTAGATATGAACGGGGATA3'+5'CACAA CTATTCTTAGTGCTGAATTCACTT3'. The membranes were washed twice under the standard Alk Phos conditions with $0.5 \mathrm{M} \mathrm{NaCl}$ at $42^{\circ} \mathrm{C}$ for 20 minutes. To test the methylation state of ERTBV, Southern blotting analysis was carried out using the C-methylation-sensitive enzyme HpaII and the partially sensitive enzyme MspI (isoschizomer of HpaII). The same probe mentioned above was prepared using a PCR-based labeling system with the PCR DIG labeling mix (Roche). To verify that complete digestion was achieved by the enzymes, a chloroplast DNA fragment, the 5.2-kb Sma-8 fragment of buckwheat [22], was used as a control probe.

\section{Sequence data}

The sequences containing Indica ERTBV have been deposited in DDBJ: accession nos. AB124591, AB124592 and $\mathrm{AB124593.}$. The reconstructed sequences for the authentic ERTBV viruses, ERTBV-A, $-\mathrm{B}$ and $-\mathrm{C}$ were deposited in DDBJ: accession nos. BR000029, BR000030 and BR000031, respectively.

\section{Authors' contributions}

MoKu and MaKa carried out the molecular genetic studies and participated in the sequence alignments. HN participated in the sequence alignment and performed the phylogenetic analysis. IU participated in the design of the study. YK conceived of the study and drafted the manuscript. YK and YS participated in its design and coordination. All authors read and approved the final manuscript.

\section{Acknowledgements}

We thank Dr. IL Ryong Choi (International Rice Research Institute, Philippines) Dr. Kaien Fujino (Hokkaido Univ.), and Ms. Kumi Saito (Hokkaido Univ.) for valuable comments. We are also grateful to Prof. Testo Mikami (Hokkaido Univ.) for providing laboratory facilities. This work was supported by Grants-in-aid for scientific research on priority area (A) Ministry of Education, Culture, Sports, Science and Technology.

\section{References}

I. Bejarano ER, Khashoggi A, Witty M, Lichtenstein C: Integration of multiple repeats of geminiviral DNA into the nuclear genome of tobacco during evolution. Proc Natl Acad Sci U S A 1996, 93:759-764.

2. Ashby MK, Warry A, Bejarano ER, Khashoggi A, Burrell M, Lichtenstein CP: Analysis of multiple copies of geminiviral DNA in the genome of four closely related Nicotiana species suggest a unique integration event. Plant Molecular Biology 1997, 35:3|3-32|.

3. Richert-Poggeler KR, Shepherd RJ: Petunia vein-clearing virus: $\mathbf{A}$ plant pararetrovirus with the core sequences for an integrase function. Virology 1997, 236:137-146.

4. Richert-Poggeler KR, Noreen F, Schwarzacher T, Harper G, Hohn T: Induction of infectious petunia vein clearing (pararetro) virus from endogenous provirus in petunia. Embo Journal 2003, 22:4836-4845.

5. Harper G, Hull R: Cloning and sequence analysis of banana streak virus DNA. Virus Genes 1998, I 7:27|-278.

6. Ndowora T, Dahal G, LaFleur D, Harper G, Hull R, Olszewski NE, Lockhart B: Evidence that badnavirus infection in Musa can originate from integrated pararetroviral sequences. Virology 1999, 255:214-220.

7. Harper G, Osuji JO, Heslop-Harrison JS, Hull R: Integration of banana streak badnavirus into the Musa genome: Molecular and cytogenetic evidence. Virology 1999, 255:207-213.

8. Jakowitsch J, Mette MF, van der Winden J, Matzke MA, Matzke AJM: Integrated pararetroviral sequences define a unique class of dispersed repetitive DNA in plants. P Natl Acad Sci U S A 1999, 96: | $324|-| 3246$.

9. Lockhart BE, Menke J, Dahal G, Olszewski NE: Characterization and genomic analysis of tobacco vein clearing virus, a plant pararetrovirus that is transmitted vertically and related to sequences integrated in the host genome. J Gen Virol 2000, 8I:1579-1585.

10. Gregor W, Mette MF, Staginnus C, Matzke MA, Matzke AJ: A distinct endogenous pararetrovirus family in Nicotiana tomentosiformis, a diploid progenitor of polyploid tobacco. Plant Physiol 2004, I 34: I I9I-I 199.

II. Harper G, Hull R, Lockhart B, Olszewski N: Viral sequences integrated into plant genomes. Annual Review of Phytopathology 2002, 40:119-136.

12. Nagano H, Kawasaki S, Kishima Y, Sano Y: Structural differences in the vicinity of the waxy locus among the Oryza species with the AA-genome: identification of variable regions. Theoretical and Applied Genetics 2000, 100:376-383.

13. Mao L, Wood TC, Yu YS, Budiman MA, Tomkins J, Woo SS, Sasinowski M, Presting G, Frisch D, Goff S, Dean RA, Wing RA: Rice transposable elements: $A$ survey of 73,000 sequence-taggedconnectors. Genome Research 2000, 10:982-990.

14. Nagano H, Kunii M, Azuma T, Kishima Y, Sano Y: Characterization of the repetitive sequences in a $200-\mathrm{kb}$ region around the rice waxy locus: diversity of transposable elements and presence of veiled repetitive sequences. Genes \& Genetic Systems 2002, 77:69-79.

15. Hibino $\mathrm{H}$,, Saleh N, Roechan M,: Transmission of two kinds of rice tungro-associated viruses by insect vectors. Phytopathology 1979, 69:1266-1268.

16. Kobayashi N,, Ikeda R,: Necrosis caused by rice tungro viruses in Oryza glaberrima and $\mathbf{O}$. barthii. Japanese Journal of Breeding 1992, 42:885-890.

17. Nagano H,, Oka A,, Kishima $Y$, Sano $Y$,: DNA sequences homologous to rice tungro bacilliform virus (RTBV) present in the rice genome. Rice Genetic Newsletter 2000, I7:103-105.

18. Hull R: Molecular biology of rice tungro viruses. Annual Review of Phytopathology 1996, 34:275-297.

19. Herzog E, Guerra-Peraza O, Hohn T: The Rice tungro bacilliform virus gene II product interacts with the coat protein domain of the viral gene III polyprotein. J Virol 2000, 74:2073-2083.

20. Felsenstein J,: Phylip Phylogenetic Inference Package. Edited by: University of Washington. Seattle; 1995.

21. Chu YE,, Oka HI,: Introgression across isolating barriers in wild and cultivated Oryza species. Evolution 1970, 24:344-355.

22. Kishima Y, Ogura K, Mizukami K, Mikami T, Adachi T: Chloroplast DNA Analysis in Buckwheat Species - Phylogenetic-Relationships, Origin of the Reproductive Systems and Extended Inverted Repeats. Plant Science 1995, 108:173-179.

23. Sherker AH, Marion PL: Hepadnaviruses and HepatocellularCarcinoma. Annual Review of Microbiology I991, 45:475-508.

24. Sawasaki T, Takahashi M, Goshima N, Morikawa H: Structures of transgene loci in transgenic Arabidopsis plants obtained by particle bombardment: Junction regions can bind to nuclear matrices. Gene 1998, 21 8:27-35.

25. Liebich I, Bode J, Reuter I, Wingender E: Evaluation of sequence motifs found in scaffold/matrix-attached regions ( S/MARs). Nucleic Acids Research 2002, 30:3433-3442.

26. Tikhonov AP, Lavie L, Tatout C, Bennetzen JL, Avramova Z, Deragon JM: Target sites for SINE integration in Brassica genomes display nuclear matrix binding activity. Chromosome Research 200 I, 9:325-337.

27. Arboleda M, Azzam O,: Inter- and intra-site genetic diversity of natural field populations of rice tungro bacilliform virus in the Philippines. Archives of Virology 2000, I 45:275-289.

28. Cabauatan PQ, Melcher U, Ishikawa K, Omura T, Hibino H, Koganezawa $\mathrm{H}$, Azzam $\mathrm{O}$ : Sequence changes in six variants of rice tungro bacilliform virus and their phylogenetic relationships. J Gen Virol 1999, 80(pt 8):2229-2237. 
29. Cabunagan RC,, Angeles ER,, Villareal S,, co-authors 16: Multilocation evaluation of advanced breeding lines for resistance to rice tungro viruses. Rice Tungro Disease Management Edited by: Chancellor T C B, Azzam $\mathrm{O}$ and Heong K L. Philippines, IRRI; 1999:45-57.

30. Laco GS, Beachy RN: Rice Tungro Bacilliform Virus Encodes Reverse-Transcriptase, DNA-Polymerase, and Ribonuclease-H Activities. Proc Natl Acad Sci U S A 1994, 9 I:2654-2658.

31. Hull R, Harper G, Lockhart B: Viral sequences integrated into plant genomes. Trends in Plant Science 2000, 5:362-365.

32. Covey SN, Al-Kaff NS: Plant DNA viruses and gene silencing. Plant Molecular Biology 2000, 43:307-322.

33. Mette MF, Kanno T, Aufsatz W, Jakowitsch J, van der Winden J, Matzke MA, Matzke AJM: Endogenous viral sequences and their potential contribution to heritable virus resistance in plants. Embo Journal 2002, 2 I:46 I-469.

34. RiceBLAST: Rice sequence database BLAST search [http:// riceblast.dna.affrc.go.jp/]

35. Thompson JD, Higgins DG, Gibson TJ: Clustal-W - Improving the Sensitivity of Progressive Multiple Sequence Alignment through Sequence Weighting, Position-Specific Gap Penalties and Weight Matrix Choice. Nucleic Acids Research 1994, 22:4673-4680

36. Kimura $M,:$ A simple method for estimating evolutionary rates of base substitutions through comparative studies of nucleotide sequences. Journal of Molecular Evolution 1980, 16: I I I-I 20.

37. Saitou N, Nei M: The Neighbor-Joining Method - a New Method for Reconstructing Phylogenetic Trees. Mol Biol Evol 1987, 4:406-425.

38. Swofford DL,: PAUP*. Phylogenetic Analysis Using Parsimony (*and Other Method). Version 4 edition. Edited by: Sinauer Association. Sunderland, Massachusetts; 1998.

Publish with Bio Med Central and every scientist can read your work free of charge

"BioMed Central will be the most significant development for disseminating the results of biomedical research in our lifetime. "

Sir Paul Nurse, Cancer Research UK

Your research papers will be:

- available free of charge to the entire biomedical community

- peer reviewed and published immediately upon acceptance

- cited in PubMed and archived on PubMed Central

- yours - you keep the copyright

Submit your manuscript here:

http://www.biomedcentral.com/info/publishing_adv.asp
BiolMedcentral 